\title{
Seismic Vulnerability Assessment of Historical Unreinforced Masonry Buildings in Osijek using Capacity Spectrum Method
}

\author{
G. PAVIĆ ${ }^{a}$, M. HAdZIMA-NYARKO ${ }^{a, *}$, I. PlašČAK ${ }^{b}$ AND S. PAVIĆ ${ }^{c}$ \\ ${ }^{a}$ Faculty of Civil Engineering and Architecture, Osijek, J.J. Strossmayer University in Osijek, \\ Department of Materials and Structures, 31000 Osijek, Croatia \\ ${ }^{b}$ Faculty of Agrobiotechnical Science, Osijek J.J. Strossmayer University in Osijek, \\ Department of Agricultural Technics, 31000 Osijek, Croatia \\ ${ }^{c}$ Faculty of Humanities and Social Sciences, Osijek, J.J. Strossmayer University in Osijek, 31000 Osijek, Croatia \\ The limitation of deformation, the desired level of bearing capacity of the structural elements and the dissipa- \\ tion of the energy produced by an earthquake ensure sufficient bearing capacity, stiffness and ductility of structures. \\ These requirements are met by buildings which are designed and constructed in accordance with the latest tech- \\ nical regulations for buildings exposed to the earthquake. Most of the existing buildings in the city of Osijek do \\ not meet these requirements. It is possible to use a capacity spectrum method for the purpose of considering \\ possible responses of such structures to earthquakes and their estimates of seismic vulnerability. Calculation of \\ seismic vulnerability by this method is based on the expected behavior of the building, obtained by overlapping the \\ demand curve and capacity curve. The performance point is the point at which the capacity curve intersects the \\ reduced response curve, at which capacity and demand are equal. The values of spectral displacement obtained for \\ the performance point of a specific building class are used as the input parameters for the fragility curve for dif- \\ ferent levels of damage. This method will be applied to the collected database of traditional unreinforced masonry \\ buildings of the city Osijek in Croatia. The database is prepared and the main characteristics of the buildings are \\ processed using geographic information system.
}

DOI: 10.12693/APhysPolA.135.1138

PACS/topics: seismic vulnerability assessment, historical unreinforced masonry buildings, GIS

\section{Introduction}

In the analyses of the vulnerability of buildings to earthquakes, the numerous aspects should be taken into consideration: the loss of bearing capacity and ustability, economic losses, and instances of serious injuries or death during the earthquake. The earthquake vulnerability of sixty secession buildings in Osijek, unreinforced masonry buildings (URM), which were selected from the city database, was estimated using analytical capacity spectrum method (CSM): HAZUS, Hazard US.

Traditional masonry buildings are one of the important items of cultural heritage [1]. Most buildings of cultural or architectural heritage are masonry buildings constructed mostly of stone or brick elements linked to limestone or limestone mortar without reinforcement. They were built before the introduction of seismic regulations [2]. In the Republic of Croatia, which lies in seismically active Mediterranean-Trans-Asian belt, there is a long-standing experience in the renewal of damaged cultural heritage masonry buildings due to seismic actions [3]. Since the first recorded earthquake in 361, there have been numerous occurances of devastaing

*corresponding author; e-mail: mhadzima@gfos.hr earthquakes in Croatia. The highest peak ground acceleration with a return period of 475 years for Croatia is $0.38 \mathrm{~g}$. The area of the city Osijek experiences less pronounced earthquake and tectonic activity. The horizontal peak acceleration $a_{g r}$ amounts to $0.112 \mathrm{~g}$ for a return period $T_{p}$ of 475 years [4]. The zones of intensified earthquake activity are located about $70 \mathrm{~km}$ southwest of the city (Dilj gora) and about $30 \mathrm{~km}$ north of the city (Bansko brdo). To date, the aforementioned areas have registered earthquakes up to $M=5.7$, with the intensity in the epicentral area amounting to around VIII ${ }^{\circ}$ MCS. The city is situated by the river and the soil is primarily sedimentary and loose with a high groundwater level. These bad soil conditions increase the effect of earthquake forces on buildings, especially on older ones whose earthquake resistance was neglected during the design and construction phases.

\section{Database of URM buildings in Osijek city}

Osijek is the city with the longest series of secession buildings in Croatia. Due to the indisputable historical and architectural values of these buildings, an assessment of their seismic vulnerability was carried out. The purpose of the building database is to provide general building analysis (number of buildings, construction year, position, number of floors, occupancy etc.), analysis of their structural elements 
(masonry, floor structures construction, roof) and implementation of the vulnerability analysis under the earthquake action. The main characteristics of the buildings in the database are processed using GIS-geographic information system (Fig. 1a). Vulnerability assessment was done for buildings which were built between 1894 and 1930 using solid brick, with bevelled roofs and ceilings supported by wooden beams. The buildings have an irregular horizontal outline, while there are no outline irregularities concerning height. Apart from the basement and ground floor, the buildings have 1 or 2 floors with an average height of $4.2 \mathrm{~m}$, making the total height of these buildings range from 6 to $17 \mathrm{~m}$ (Fig. 1b). The purpose of these buildings is mixed: residential, public and commercial.

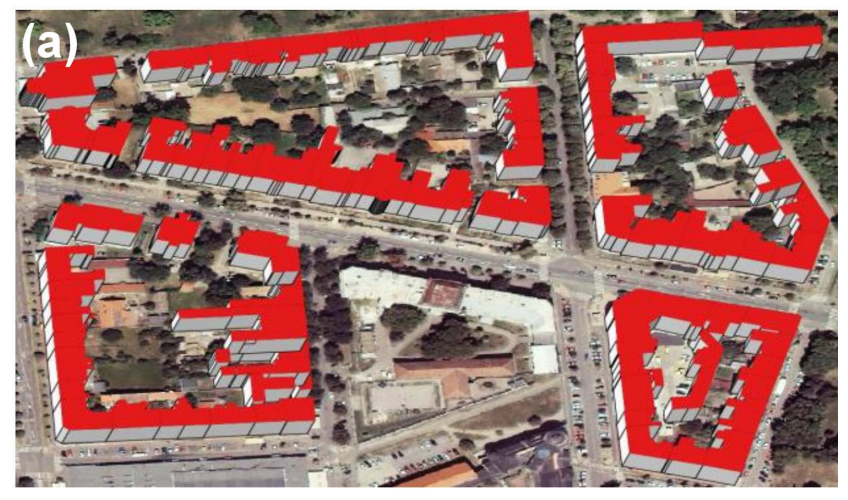

(b)

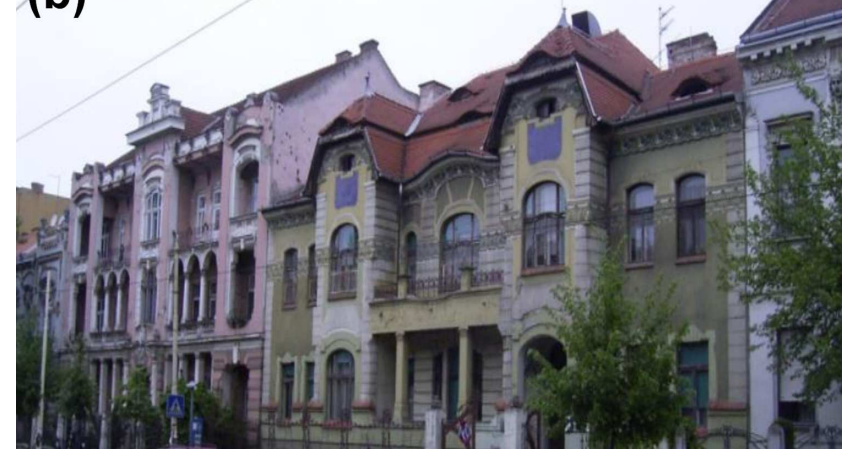

Fig. 1. Secession buildings analyzed: (a) using GIS and (b) view of the representative buildings.

\section{Capacity spectrum method}

The capacity spectrum method (CSM) is based on assumptions that the maximum lateral storey displacement efficiently describes the seismic response of the building and that the maximum lateral storey displacements are dominated by deformations of the fundamental mode of the originally elastic system [5]. Building vulnerability assesment is comprised of predicting the structural response to excitation of a certain intensity level.

The input parameters are earthquake intensity indicators (MMI - modified Mercalli intensity scale) and response indicators (damage-displacement parameters).
A nonlinear static analysis is used on an SDOF model, which is an equivalent representation of specific building typology and earthquake intensity. This analysis is also knows as the pushover method, which is used to determine the ability of the building to withstand a given ground motion [6].

Structural bearing capacity is described with capacity curves which are determined using control points: design capacity, yield capacity and ultimate capacity. The behavior of the bearing system is observed either through changes in roof displacement in relation to the cross force or through storey drifts. The intersection of reduced seismic demand and capacity curves is the performance point, which approximates the response of the building to a given load, i.e. the point indicates the conditions under which the earthquake capacity of the building are equal to the earthquake requirement for the building exposed to the selected earthquake.

Probabilty of building damage or collapse is calculated using fragility functions. The values of spectral displacement $S_{d}$ for different damage values (slight, moderate, extensive, complete or no damage), which were obtained for performance point of certain builiding class, denote the abscissa in the coordinate system [7], while the ordinate is displayed by the conditional values denoting the damage condition either being reached $P\left(\left[D_{s}=d_{s}\right]\right)$ or exceeded $P\left(\left[D_{s}>d_{s}\right]\right)$ :

$$
P\left(d_{s} \mid i m\right)=\left\{\begin{aligned}
& 1-P\left(D_{s} \geq d_{s} \mid i m\right) \\
& i=0 \\
& P\left(D_{s}\right.\left.\geq d_{s} \mid i m\right)-P\left(D_{s} \geq d_{s(i+1)} \mid i m\right) \\
& 0<i<n \\
& P\left(D_{s}\right.\left.\geq d_{s} \mid i m\right) \\
& i=n
\end{aligned}\right.
$$

Thereby, fragility curves are obtained using the lognormal distribution of the spectral displacement median $\mu_{d s}$ and the standard deviations of spectral displacement $\beta_{d s}$. Their calculation for each marginal condition implies the implementation of optimization algorithms, thus taking into consideration the variabilites for structural damage levels, bearing capacity curves and requirements spectra. Damage probability curves are converted into Damage Probability Matrices by using Eq. (1), from which probability values of individual damage degree $P\left(d_{s} \mid \mathrm{im}\right)$ are obtained, which correspond to the damage probability matrix. In Eq. (1), the following symbols are used: $i m$ is the level of intensity measurements, $d_{s}$ displays the structural damage level, and $D_{s}$ stands for the state of the damage. The classification of buildings was selected in accordance with the specified building characteristics: M5.v_L (unreinforced masonry - old bricks); v-masonry vaults; L-low rise, 12 stories) [8]. Damage is calculated and compared for earthquake intensity levels $\mathrm{VII}^{\circ}, \mathrm{VIII}^{\circ}$, and $\mathrm{IX}^{\circ}$ as well as for the related accelerations $a_{g}$ (MKS-64). According to EN 1998-1:2004 [9], the type of ground soil B 


\section{M5.v_L Intensity VII}

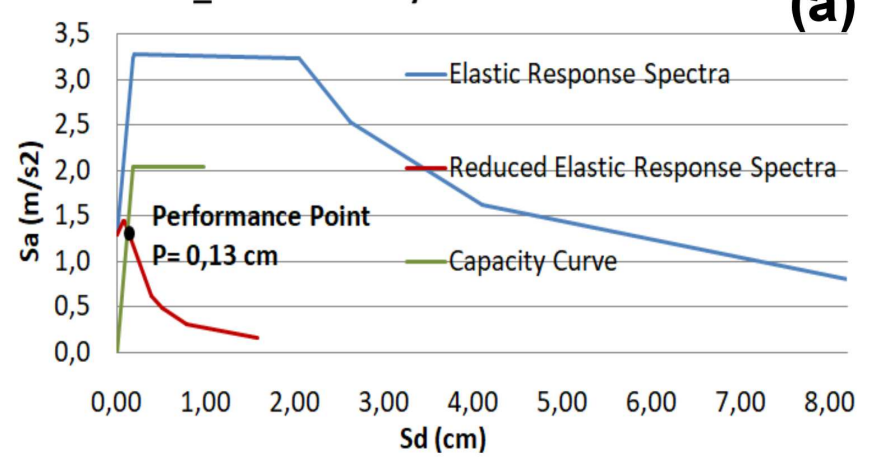

M5.v_L Intensity VIII

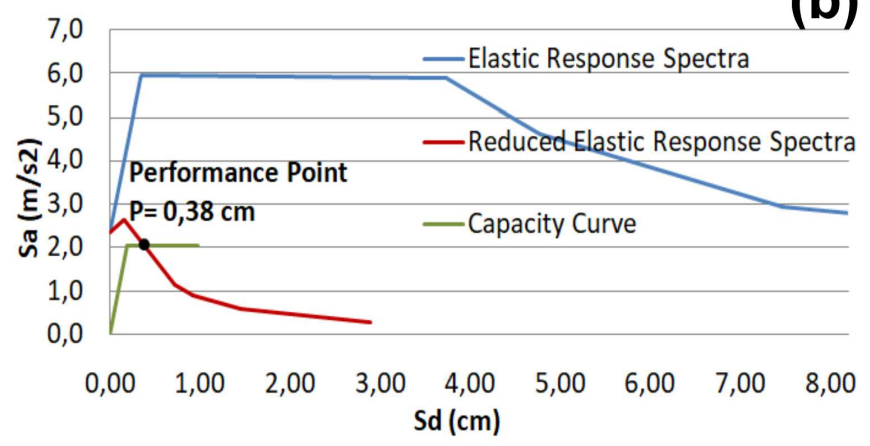

\section{M5.v_L Intensity IX}

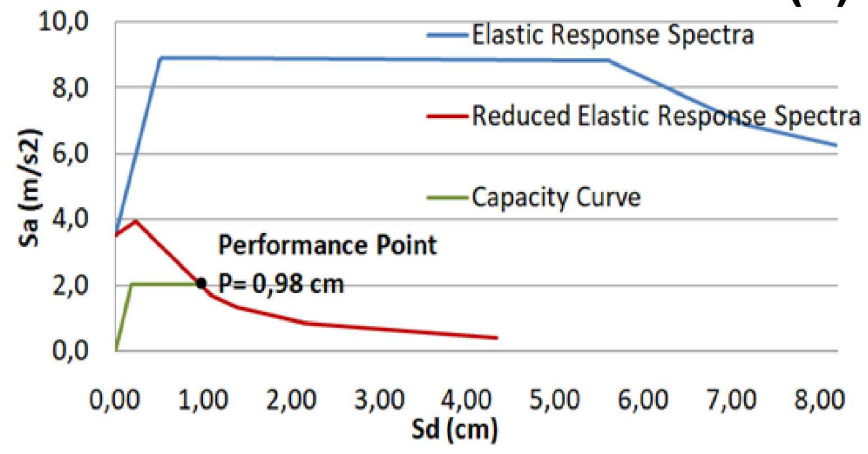

Fig. 2. Curve and performance point for intensity (a) $\mathrm{VII}^{\circ}$, (b) $\mathrm{VIII}^{\circ}$ and (c) $\mathrm{IX}^{\circ}$.

and corresponding parameters for adopted spectrum type 1 (earthquakes $M>5.5$ ) were used for the calculation of the elastic response spectrum. Periods of $0.2 \mathrm{~s}$, with intervals of $0.5 \mathrm{~s}$, were used for the calculation of elastic response spectrum. Reduced elastic response spectrum is calculated by reduction of the elastic response spectrum using relation $(2)$ :

$$
\begin{aligned}
& T<T_{c}: R_{\mu}=(\mu-1) \frac{T}{T_{c}}+1, \\
& T \geq T_{c}: R_{\mu}=\mu,
\end{aligned}
$$

where $T$ is the oscillation period $\mathrm{SDO}, T_{c}$ represents the period when the constant spectral displacement ends, $R_{\mu}$ shows the reduction factor during ductility, and $\mu$ is the ductility factor (ratio between the maximum displacement and the displacement during yielding). For M5.v_L the values are as follow: $\mu=5.17$ and $T(s)=0.192[8]$. The calculation of Capacity Curves in a nonlinear static analysis involved the control points for M5.v_L: $A y=$ $0.208 \mathrm{~g} ; D_{y}=0.0019 \mathrm{~m} ; D_{u}=0.0098 \mathrm{~m} \mathrm{[8]}$.

Performance point values are calculated for certain levels of earthquake intensity. The results of the following terms are shown in Fig. 2: elastic response spectra, reduced elastic response spectra, capacity curve and performance point for intensities $\mathrm{VII}^{\circ}, \mathrm{VII}^{\circ} \mathrm{I}$ and $\mathrm{IX}^{\circ}$, respectively.

The calculation of fragility curve was made according to Risk-UE Project [10], while marginal conditions, i.e., the damage levels represented (slight, moderate, extensive, complete), were adopted according to d'Ayala [7]. For the construction of damage fragility curves the following are defined: bilinear capacity spectra in accelerationdisplacement form (based on the yield point $D_{y} A_{y}$, end point $D_{u} D_{a}$, and bearing capability curves) and damage threshold levels according to the terms: $S_{d_{1}}=0.7 D_{y}$; $S_{d_{2}}=D_{y} ; \quad S_{d_{3}}=D_{y}+0.25\left(D_{u}-D_{y}\right) ; S_{d_{4}}=D_{u}$. Cumulative probability $C P$ for every threshold level, which is equal to or higher than the specific damage level $k$ for individual spectral displacements $S_{d}$, was taken from [11].

Finite element analysis includes the following for every damage level: regression analysis for $S_{d}-C P$, spectral displacement median $\mu_{d s}$, and lognormal standard deviations $\beta_{d s}$. The calculated fragility curves for an earthquake intensity $\mathrm{IX}^{\circ}$ is shown in Fig. 3.

In order to evaluate the earthquake damage with regard to individual levels of damage, fragility curve is converted into damage probability matrix using Eq. (1), and the results are shown in Table I.

Damage degree probability matrix for M5.v_L.

\begin{tabular}{c|c|c|c|c|c}
\hline \hline Intensity & 0 & 1 & 2 & 3 & 4 \\
\hline VII $^{\circ}$ & 0.5 & 0.284246 & 0.14887 & 0.044146 & 0.022738 \\
VIII $^{\circ}$ & 0.14649 & 0.249018 & 0.277344 & 0.155739 & 0.171409 \\
IX $^{\circ}$ & 0.023829 & 0.09245 & 0.198978 & 0.192644 & 0.492099
\end{tabular}




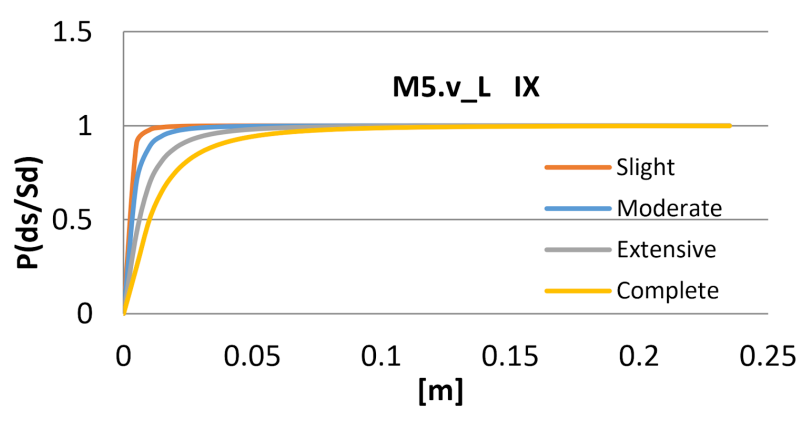

Fig. 3. Fragility curve for intensity $\mathrm{IX}^{\circ}$.

\section{Comparison of results}

The probabilities of reaching a certain damage level of traditional unreinforced masonry buildings, calculated using CSM, are shown in the Fig. 4 for three levels of intensity. The probability that the damage threshold level will not be reached during an earthquake of a particular intensity is as follows: $50 \%$ for an intensity VII ${ }^{\circ}$ (Fig. 4a), $15 \%$ in the case of an intensity VIII ${ }^{\circ}$ (Fig. $4 \mathrm{~b}$ ), and $2 \%$ if an earthquake with intensity $\mathrm{IX}^{\circ}$ (Fig. 4c) were to occur.

For intensity level $\mathrm{VII}^{\circ}$, the damage probability is reduced by increasing the degree of damage level, while in the case of intensitiy level $\mathrm{IX}^{\circ}$, the increase in the degree of damage levels increased the damage probability. In the case of intensity level VIII ${ }^{\circ}$ earthquakes (Fig. 4b), the highest probability $(28 \%)$ for reaching the moderate damage level is expected. Furthermore, the damage percentage is linearly reduced towards the no damage level as well as experiencing a stair-step growth from the extensive to the complete level.

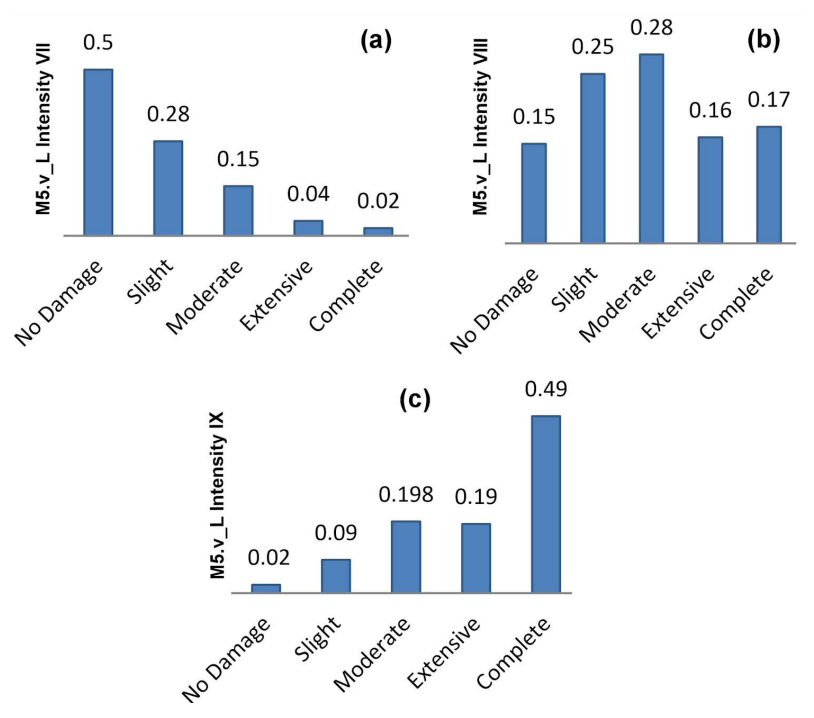

Fig. 4. The probability of reaching damage levels for earthquake intensitiy levels: (a) $\mathrm{VII}^{\circ}$, (b) $\mathrm{VIII}^{\circ}$ and (c) $\mathrm{IX}^{\circ}$.
The loss of intitial bearing capacity and stiffness of the masonry is affected by: various predictable and unpredistable effects, degradation of intitial properties of the masonry, and a number of uncertainties regarding the realization of a sufficient connection between the masonry elements. All that causes a highly nonlinear behaviour of the masonry and even a situation where the damage threshold level are achieved during a higher earthquake intensity. The probability of reaching the damage threshold level desribed as moderate in the case of analyzed buildings are as follows: $15 \%$ for earthquake intensity $\mathrm{VII}^{\circ}, 28 \%$ for earthquake intensity $\mathrm{VIII}^{\circ}$, and $19.8 \%$ when the earthquake intensity is IX ${ }^{\circ}$. Due to their thickness, the masonry have relatively small natural periods of vibration. However, the size of earthquake response indicators is also influenced by the unfavorable conditions of the foundations and the ground plan irregularities of the aforementioned buildings. The interaction of these parameters in traditional unreinforced masonry buildings in Osijek gives a building collapse probability of $2 \%$ during an intensity $\mathrm{VII}^{\circ}$ earthquake, $17 \%$ in the case of an intensity $\mathrm{VIII}^{\circ}$, and $49 \%$ if an earthquake of intensity $\mathrm{IX}^{\circ}$ were to occur.

\section{Conclusion}

The seismic response of traditional unreinforced masonry buildings of the city Osijek was calculated using capacity spectrum methods. The displacement of the top floor is considered as the earthquake response indicator, whereas its size was used for classifying the degrees of damage levels. Although they were not designed for seismic loading, the assessed buildings have relatively high seismic resistance due to their low height and massive masonry. Even in the event of an intensity $\mathrm{VIII}^{\circ}$, the probability is $17 \%$ that the earthquake induced stress would create cracks which may lead to the collapse of the building, i.e., that the damage level complete be reached.

By using nonlinear static analysis, a satisfactory estimate of the bearing capability of unreinforced masonry buildings has been achieved. Based on the aforementioned estimate, using clear and detailed algorithms, the earthquake damage of assessed buildings is estimated. CSM has proven to be a relatively simple and yet sufficiently precise analytical method, whose results may be of importance for maintenance, reinforcement or adaptation of masonry buildings of architectural heritage.

\section{References}

[1] A.I. Carhoglu, P. Usta, K.A. Korkmaz, Acta Phys. Pol. A 127, 1083 (2015).

[2] M. Hadzima-Nyarko, V. Mišetić, D. Morić, J. Cult. Herit. 28, 140 (2017).

[3] M. Hadzima-Nyarko, T. Kalman-Šipoš, Earthq. Struc. 13, 365 (2017).

[4] M. Herak, in: Proc. IV Conf. Croatian National Platform for Disaster Risk Reduction, Zagreb 2012, p. 4. 
[5] K. Peter, M. Badoux, Application of the capacity spectrum method to R.C. Buildings with bearing walls, in: Proc. 12th World Conf. Earthquake Engineering, Auckland 2000

[6] S.A. Freeman, The capacity spectrum method as a Tool for Seismic Design, in: Proc. 11th European Conf. Earthquake Engineering, Paris 1998.

[7] D.F. D'Ayala, Assessing the sesmic vulnerability of masonry buildings, in: Handbook of Seismic Risk analysis and management of civil infrastructure systems, Eds. K. Goda, S. Tesfamariam, Woodhead Publ., 2013, p. 334.

[8] ELER v3.0, Technical Manual and Users Guide, Bogazici University, 2010.

[9] EN 1998-1:2004, Design of structures for earthquake resistance, Part I: General rules, seismic actions and rules for buildings, CEN - European Committee for Standardization, Brussels (accepted as Croatian norm HRN EN 1998-1:2011), (2004).
[10] P. Mouroux, E. Bertrand, M. Bour, B. Le Brun, S. Depinois, P. Masure, in: 13th World Conf. Earthquake Engineering, Vancouver 2004, Pap. No. 3329.

[11] Z.V. Milutinović, G.S. Trandafilovski, The European RISK-UE project: An advanced approach to earthquake risk scenarios with applications to different European towns, in: WP4 Handbook: Vulnerability of current buildings, 110, Contract: EVK4-CT-200000014, 2003 